\title{
Effect of Radiation Sterilization on the Physicochemical Properties and Microbial Load of Amoxicillin Tri-Hydrate Powder
}

\author{
M Humayun Kabir ${ }^{1}$, Anisur Rahman Khan ${ }^{1 *}$, Marufa Zerin Akhter ${ }^{1}$, MAbdul Malek ${ }^{1}$, Nazmul Alam Chowdhury ${ }^{2}$ \\ and Naiyyum Choudhury ${ }^{3}$
}

${ }^{1}$ Department of Microbiology, University of Dhaka, Dhaka 1000, Bangladesh, ${ }^{2}$ Institute of Food \& Radiation Biology (IFRB), Atomic Energy Research Establishment (AERE), PO Box 3787, Dhaka 1000, Bangladesh, ${ }^{3}$ Bangladesh Atomic Energy Commission (BAEC), 4 Kazi Nazrul Islam Avenue, Dhaka 1000, Bangladesh

[Received 29 August 2006; Accepted 07 October 2006]

\begin{abstract}
Amoxicillin tri-hydrate powder was irradiated at different doses of gamma radiation, and the subsequent changes in terms of physicochemical properties and potency were evaluated. A dose of 0.5 Mrad was found to be enough to sterilize the powder, which had an initial bacterial count of $6.2 \times 10^{1} \mathrm{cfu} / \mathrm{ml}$. The original snowwhite colour of the powder changed to light brown upon irradiation doses over $2.5 \mathrm{Mrad}$. The pH decreased upon increase of radiation dose. The iodometric titration assay showed only a little variation in potency (about 1-4\%) of the test materials after irradiation. High performance liquid chromatography (HPLC) analysis of irradiated amoxicillin tri-hydrate powder showed no marked loss of potency by irradiation even up at a dose of 10.0 Mrad. No degradation product and extra peak was found at this high dose. The results indicated that dried powder of amoxicillin tri-hydrate is stable after sterilization by irradiation.
\end{abstract}

Keywords: Amoxicillin tri-hydrate, Irradiation, Radiosterilization

Amoxicillin tri-hydrate $\left(\mathrm{C}_{16} \mathrm{H}_{19} \mathrm{~N}_{3} \mathrm{O}_{5} \mathrm{~S} .3 \mathrm{H}_{2} \mathrm{O}\right)$ is a white or almost white crystalline powder. Chemically, it is (6R)-6-( $\alpha$-D-phydroxyphenylglycylamino) penicillanic acid tri-hydrate. It contains not less than $95.0 \%$ and not more than $100.5 \%$ of $\mathrm{C}_{16} \mathrm{H}_{19} \mathrm{~N}_{3} \mathrm{O}_{5} \mathrm{~S}$, calculated with reference to the anhydrous substance. Oral amoxicillin is better absorbed than ampicillin and yields higher blood levels ${ }^{1}$. It is therefore a preferred antibiotic over ampicillin for the treatment of typhoid, bronchitis, urinary tract infection (UTI), sub acute bacterial endocarditis (SABE) and gonorrhoea. It has the antibacterial activity and is usually used in capsules, oral suspensions and intramascular (IM) or intravenous (IV) injections. Therefore these preparations are required to be sterile ${ }^{2-3}$. Various conventional sterilization methods such as dry heat, moist heat, filtration etc. although practiced for many years, have limitations in certain situations and hence these techniques cannot be applied universally ${ }^{4}$. From industrial viewpoint, sterilization of heat labile compounds by irradiation is advantageous. The radiosterilization involves the application of sufficient ionising energy emitted by radioisotope (e.g., ${ }^{60} \mathrm{Co}$ and ${ }^{137} \mathrm{Cs}$ ) to render a product free of microorganisms regardless of the duration or, condition of storage (assuming of course that recontamination is prevented) ${ }^{5}$. Gamma rays from radioactive isotopes have good penetrating power, high sterilizing efficiency, minimum damage to irradiated materials and satisfactory production efficiency ${ }^{6}$. Sterilization by ${ }^{60} \mathrm{Co}$ gamma irradiation has proved its utility as an efficient and economic method of terminal sterilization for some pharmaceuticals in solid state.

In Bangladesh, research reports on microbiological quality and radiosterilization of pharmaceutical raw material is scarce. The present study was undertaken to determine an effective radiation dose for sterilizing the antibiotic amoxicillin tri-hydrate powder and to determine its stability by observing the physical and chemical changes, if any, upon radiation at high levels.

The non-sterile amoxicillin tri-hydrate powder was supplied by a pharmaceutical industry (Renata Ltd, Bangladesh). Five grams of each sample was aseptically sealed in pre-sterilized (3.0 Mrad) polyethylene sachets and then irradiated at five different doses of 0.5, 1.0, 2.5, 5.0 and $10.0 \mathrm{Mrad}$ from a ${ }^{60} \mathrm{Co}$ gamma irradiation source. All irradiated samples along with the control (un-irradiated sample) were stored in ambient temperature.

The total viable bacteria, coliform and fungi present in the irradiated and un-irradiated amoxicillin tri-hydrate samples were cultivated on nutrient agar (NA), MacConkey agar (MAC) and potato dextrose agar (PDA) respectively. Standard pour plate technique was employed for determining total viable counts of microorganisms ${ }^{1,7}$. In case of very low microbial counts, millipore filtration technique was employed.

Biopotency was determined by employing standard agar diffusion method on petri-dishes $(140$ x $20 \mathrm{~mm})$ containing Medium $\mathrm{A}^{8}$ and

*Corresponding author:

Dr. Anisur Rahman Khan, Professor \& Chairman, Department of Microbiology, University of Dhaka, Dhaka 1000, Bangladesh

Tel (Office): (02) 9661900-73/7730, 7740; Tel (Home): (02) 9571211; Cell: 01199 156618; Fax: +880 (02) 8615583; E-mail: anis37@yahoo.com 
Bacillus cereus (NTCC 10320) as test organism. Two different concentrations, high $(4 \mu \mathrm{g})$ and low $(1 \mu \mathrm{g})$, were prepared in sterile distilled water for both standard and test samples. Disc-diffusion method $^{9}$ was employed for the determination of antibiotic susceptibility against selected organisms using Medium $\mathrm{A}^{8}$. Amoxicillin tri-hydrate discs (30 $\mu \mathrm{g} /$ disc; Oxoid, USA) were used for sensitivity tests. These were sealed in polythene pouches and irradiated at different doses of gamma radiation. Some unirradiated discs were kept as control.

Iodometric method was used for the determination of radiationinduced degradation of amoxicillin tri-hydrate raw materials ${ }^{8}$. The potency of the samples was calculated in $\mathrm{mg} / \mathrm{mg}$ or $\mathrm{mg} / \mathrm{mg}$ using the standard formula for iodometric method ${ }^{8}$.

HPLC method was performed to test the integrity of the samples as described in the United States Pharmacopoeia ${ }^{10}$ and the specific manual concerned ${ }^{11}$. The $\mu$ Bondapack C18 (3.9 x $\left.300 \mathrm{~nm}\right)$ was used with Bonded phase (silicon) column packing. Each of the $30 \mathrm{ml}$ standard and irradiated test solutions was injected in the injector and the flow rate was adjusted at $1.5 \mathrm{ml} / \mathrm{min}$. The absorbance unit full scale (AUFS) and the chart speed (CS) were fixed at 0.5 and $0.25 \mathrm{~cm} / \mathrm{min}$, respectively. The peak width and attenuation of the chromatograph were adjusted accordingly 0.5 and 16.0, where the stop time of the system was fixed at 10 minutes. The wavelength of $U V$ detector ( $\lambda_{\max }$, model water 486 ) was $230 \mathrm{~nm}$. The HPLC analyser (model water, millipore) was assembled with an integrator (waters, 746 data millipore) and a pump (water associates chromatography pump, Model 510) whose operating range was 5,000 psi and pressure limit was $15 \mathrm{ml} / \mathrm{min}$. At the end of the stop time of all the samples, the printed record of the recorder was preserved. The potency of the pharmaceutical raw materials was quantified by measuring the area of a peak on a chart recorder trace. The formula for the determination of the potency was as follows:

Standard sample weight $x$ Test sample peak area $x$ Potency of the standard

Potency $=\frac{\text { Test sample weight } x \text { Standard sample peak area }}{\text { Tan }}$
Amoxicillin tri-hydrate samples were treated with five different doses of gamma radiation in the dry powdered state to find out the minimum effective irradiation dose for complete elimination of microbes. The results showed 0.5 Mrad to be effective minimum radiation dose to eliminate all viable bacteria with an initial load of $6.2 \times 10^{1}$ bacteria (Table 1). Although complete elimination of microbes at this particular lot was achieved with a dose of $0.5 \mathrm{Mrad}$, it might vary from lot to lot as radiosterilization is dependent on the initial total load of microbes and the presence of radio-resistant organisms in a particular lot. Muszynski et al. ${ }^{12}$ carried out a similar study on sterility and antibacterial activity of several antibiotics (including some penicillins and their salts, gramicidin and neomycin) using radiosterilization by gamma irradiation. Tests recommended for checking their sterility and activity were also carried out. The results proved that the penicillins, gramicidin and neomycin analysed could be sterilized by gamma irradiation with a dose of $2.5 \mathrm{Mrad}$ (25 kGy) without any detrimental effect on their properties and antibacterial activity.

In the present study, remarkable change in the colour of amoxicillin tri-hydrate powder was observed upon irradiation, which was dose dependent (Table 1). This change in colour upon radiation might be attributed to the presence of traces of free radicals of relatively longer life and surface changes because their physicochemical parameters did not show any significant change. The $\mathrm{pH}$ of the irradiated sample gradually decreased from 3.8 to 3.6 with the increase in irradiation dose (Table 1). The British Pharmacopoeia (BP) $)^{13}$ states that a $0.2 \% \mathrm{w} / \mathrm{v}$ solution in water of amoxicillin tri-hydrate has a pH between 3.5 and 5.5 and the United States Pharmacopoeia (USP) ${ }^{10}$ states that a $0.2 \% \mathrm{w} / \mathrm{v}$ solution of amoxicillin tri-hydrate has a $\mathrm{pH}$ in between 3.5 and 6.0. The present study revealed that the $\mathrm{pH}$ of the irradiated samples was within the range as stated by the BP and the USP.

It was observed, using agar-diffusion biopotency test, that the potency of the irradiated samples was not lost even at a dose of 10.0 Mrad. After irradiation the residual potency ranged from $95.00 \%$ to $97.11 \%$. Similar potency result was observed in the disk-diffusion tests where the diameter of zones of inhibition of

Table 1. Microbial load, colour, $p H$, zone of inhibition and potency of amoxicillin tri-hydrate powder samples after irradiation at different doses

\begin{tabular}{|c|c|c|c|c|c|c|c|c|}
\hline \multirow{2}{*}{$\begin{array}{l}\text { Irradiation } \\
\text { dose (Mrad) }\end{array}$} & \multicolumn{3}{|c|}{ Total viable microbial count (cfu/g) } & \multirow[t]{2}{*}{ Colour } & \multirow[t]{2}{*}{$\mathrm{pH}$} & \multirow{2}{*}{$\begin{array}{c}\text { Zone of } \\
\text { inhibition }^{\mathrm{a}} \\
(\mathrm{mm})\end{array}$} & \multicolumn{2}{|c|}{ Potency (\%) } \\
\hline & Total bacteria & Coliform & Fungi & & & & $\begin{array}{c}\text { Agar diffusion } \\
\text { method }\end{array}$ & $\begin{array}{c}\text { Iodometric } \\
\text { method }\end{array}$ \\
\hline 0.0 & $6.2 \times 10^{1}$ & nil & nil & snow white & 3.9 & 16.4 & 96.63 & 98.92 \\
\hline 0.5 & nil & nil & nil & white & 3.8 & 16.2 & 95.46 & 97.69 \\
\hline 1.0 & nil & nil & nil & white & 3.8 & 16.2 & 96.17 & 98.74 \\
\hline 10.0 & nil & nil & nil & light brown & 3.6 & 16.3 & 95.00 & 97.45 \\
\hline
\end{tabular}

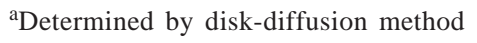


un-irradiated and irradiated amoxicillin discs was almost the similar. This indicates that even at an extreme dose (10.0 Mrad ) of gamma irradiation the potency of amoxicillin never changes.

The iodometric titration results of un-irradiated and irradiated samples were nearly similar (Table 1). The residual potency ranged from $97.45 \%$ to $98.82 \%$, which gave a preliminary indication of stability of irradiated amoxicillin tri-hydrate powder. However, as this was not a confirmatory test for the determination of degraded products, HPLC analysis was carried out to identify any degraded product of irradiated samples. It was found that the retention times and peak areas of un-irradiated and irradiated samples were nearly similar and no extra peak was observed in the irradiated powdered samples even at 10.0 Mrad. Even the potencies of irradiated samples were similar compared to the potency of the un-irradiated sample that ranged from $96.93 \%$ to $98.10 \%$ (Table 2). According to $\mathrm{BP}^{13}$, the potency of amoxicillin tri-hydrate ranges from $90.00 \%$ to $100.50 \%$. From the iodometric and the HPLC analyses of the present study it could be concluded that the potency of irradiated amoxicillin tri-hydrate powder samples were within the pharmacopoeial limit.

Table 2. Summary of HPLC analysis of un-irradiated and irradiated samples of amoxicillin tri-hydrate powder

\begin{tabular}{lccc}
\hline Irradiation dose (Mrad) & $\begin{array}{c}\text { Retention } \\
\text { time (min) }\end{array}$ & Peak area & Potency (\%) \\
\hline Un-irradiated & 4.41 & 233,831 & 97.30 \\
0.5 & 4.40 & 237,259 & 97.07 \\
1.0 & 4.40 & 234,776 & 98.10 \\
2.5 & 4.40 & 230,968 & 97.77 \\
5.0 & 4.39 & 236,158 & 97.02 \\
10.0 & 4.38 & 233,932 & 96.93 \\
\hline
\end{tabular}

Sterilization dose for any pharmaceutical product is not an absolute one. This is due to level of sterility requirement of different pharmaceutical products and effect on sterilizing dose upon their clinical, physical and chemical properties of the products that often restrict or even prohibit the desired level of dose treatment ${ }^{14}$. The sterility requirement may be partial or absolute depending on its usage. Once it is fixed and accepted, microbiological parameters may then be assessed for arriving at the doses of sterility. The results of biopotency, iodometric titration and the HPLC in the present study clearly indicated that the radiation induces no degradation product of amoxicillin tri-hydrate even at 10.0 Mrad dose of gamma radiation, hence this dose could be safely used to sterilize amoxicillin tri-hydrate powder in the dry state. Ionising radiation offers many advantages over the conventional methods of sterilization and has proved to be invaluable in sterilization of a wide variety of medical and pharmaceutical products ${ }^{15-16}$.

Radiation sterilization of medical and pharmaceutical products is now a fully developed and profitable industry in many countries. Bangladesh has made a modest beginning in this respect in 1974. Institute of Food and Radiation Biology (IFRB) of Bangladesh Atomic Energy Commission (BAEC) has been offering radiation sterilization services to many governmental and autonomous organizations and private pharmaceutical companies since 1981. The medical and pharmaceutical raw materials that are un-sterilized or imported un-sterilized may be foreseen for radiation sterilization treatment if found suitable by appropriate tests. There is no national code of practice for the manufacture of medical products in Bangladesh. The microbiological status of the medical products has to be surveyed from time to time. Hence, there is a great opportunity of research on radiation sterilization on different pharmaceutical product and raw materials in our country. The present study is among the very first attempts in this regard and is indispensable in the field of research on radiosterilization in Bangladesh.

\section{References}

1. Brooks GF, Butel JS \& Morse SA. 1995. Jawetz, Melnick, \& Alderberg's Medical Microbiology, 22 ${ }^{\text {nd }}$ edn. McGraw \& Hill Co Inc, New York.

2. Lehninger AL. 1982. Principles of Biochemistry, $3^{\text {rd }}$ edn, CBS Publishers \& Distributors, New Delhi.

3. Gennaro AR. 1985. Remington's Pharmaceutical Sciences, $17^{\text {th }}$ edn, Mack Publishing Co, Eastern Pennsylvania.

4. Armburst RF. 1974. Radiosterilization in the precessing of non-sterile pharmaceutical preparations and basic materials. In Radiosterilization of Medical products, pp 379-380. Proceedings on the Symposium of Ionising Radiation for Sterilization of Medical Products and Biological Tissues, Bombay, India, 9-13 ${ }^{\text {th }}$ December 1974. International Atomic Energy Agency (IAEA), Vienna, Austria.

5. Goldblith SA. 1966. Radiation sterilization of food. Nature. 210(34): 433-434.

6. Cooper JW, Gunn C \& Carter SJ. 1970. Sterilization by radiation. In Cooper \& Gunn's Dispensing for Pharmaceutical Students (Revised), pp 623-633. Pitman Madical, Tunbridge Wells.

7. Cappuccino JG \& Sherman N. 1996. Microbiology: A Laboratory Manual, $4^{\text {th }}$ edn. The Benjamin Cummings Publishing Co Inc, San Francisco.

8. BP. 1980. British Pharmacopoeia, Vol. I \& II, pp 32-32, 374-75, 471-72, 664-65. Her Majesty’s Stationary Office (HMSO), London.

9. Bauer AW, Kirby WMM, Sherris JC \& Turck M. 1966. Antibiotic susceptibility testing by a standardized single disc method. Am J Clin Pathol. 45: 493-496.

10. USP. 1995. United States Pharmacopoeia, Vol 23. Mack Publishing Co, Eastern Pennsylvania.

11. Anonymous. 1995. The Manual of Renata Limited. Quality Control Department, Section VII, Renata Limited, Dhaka.

12. Muszynski Z, Dlugaszewska J, Marciniec B, Plotkowiak Z, PopielarzBrzezinska M \& Ogrodowczyk M. 2002. Sterility and antibacterial activity of some antibiotics sterilized by irradiation. Acta Pol Pharm. 59(6): 433-435.

13. BP. 1993. British Pharmacopoeia, Vol. I \& II, pp 196-197, 434, 438, 443. Her Majesty's Stationary Office (HMSO), London.

14. Patel KM. 1982. Proceedings on National Workshop on Radiatyion Sterilization of Biochemical Products and Pharmaceuticals, pp 4557. BARC, Bombay, India.

15. Pelczar MJ, Chan ECS \& Krieg NR. 1986. Microbiology, $5^{\text {th }}$ edn, pp 138-39. McGraw Hill Book Co Inc, San Francisco.

16. Christensen EA, Holm NW \& Juul FA. 1967. Radiosterilization of medical devices and supplies: Radiosterilization of medical products, pp 265-283. Proceedings of the IAEA Symposium, Budapest, Hungary. International Atomic Energy Agency (IAEA), Vienna, Austria. 